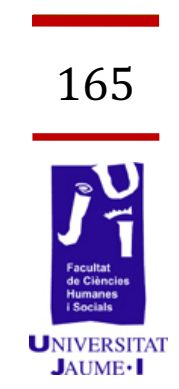

\title{
Género, Estética y Diseño Urbano ¿Crear espacios para vivir mejor?
}


Las sociedades actuales viven inmersas en una espiral de solipsismo que queda reflejada en los modos de vida y en las formas de construir los espacios. Cada vez con una mayor frecuencia, las viviendas y las ciudades han adoptado unas formas que propician el mayor de los individualismos por parte de quienes las habitan, y por tanto un alejamiento constante de la sociedad, con la respectiva pérdida progresiva de los sentimientos de pertenencia a colectivos sociales. El diseño urbano juega un papel fundamental, en tanto que su desarrollo posibilita formas de vivir y de habitar diferentes, que sean capaces de dar respuesta a las necesidades reales de todos los habitantes de las ciudades, y muy especialmente a ese colectivo que las estructuras sociales han procurado mantener al margen a lo largo de la historia: las mujeres.

Paraules clau: Género, Diseño, Arquitectura, Estética, Crítica Filosófica.

\section{Introducción}

Son muchos los estudios con perspectiva de género que han aborado un sinfín de temáticas en las últimas décadas, desde el auge de los gender studies en las facultades estadounidenses a partir de la década de los setenta del pasado siglo. Sin embargo, han sido pocos -aunque sus resultados son excelentes- los autores y las autoras que han profundizado en el punto de convergencia entre el género y la arquitectura $-y$ lo mismo sucede entre el urbanismo y el género. En ese sentido, este artículo pretende ser una aproximación a la situación actual entre ambos conceptos y ejercer una mirada crítica hacia las formas de construir los espacios que las sociedades han desarrollado hasta nuestros días, y como precisamente esas formas -que tienen un eminente carácter estéticocondicionan nuestras formas de vivir, de habitar y también de relacionarnos y participar socialmente. Cabe destacar que parte del contenido de este artículo surge de una investigación mucho más extensa, un trabajo final de grado de la primera promoción de la titulación de Historia y Patrimonio, especialidad en arte, de la Universitat Jaume I, y de la titulación de Humanidades: estudios interculturales, especialidad en filosofía en la misma universidad. Podríamos decir que de esta combinación, de arte y filosofía, surge la necesidad personal de entender mejor los espacios en los que vivimo adentrándonos con más profundidad en ellos y sus significados, y en definitiva como la teoría y el pensamiento -las estructuras sociales patriarcales- acaban deviniendo en realidades físicas -elementos constructivos sujetos a un juicio y crítica estéticos- que influyen de forma directa en los aspectos de género de análisis de las sociedades contemporáneas. 
III. Objetivos

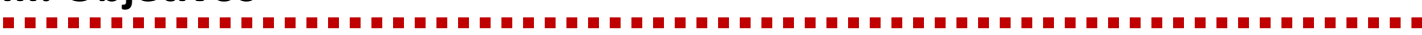

Los objetivos de este artículo de investigación consisten en acercarnos a la dimensión teórica del hecho de habitar los espacios urbanos desde una perspectiva de género, pero sin olvidarnos del inseparable carácter estético de estos espacios. En ese sentido, se conforma como una revisión crítica del entorno actual urbanístico y los fundamentos de este para su desarrollo, observando y analizando el papel de las mujeres en estos aspectos.

\section{Material y método}

La metodología utilizada para llevar a cabo esta investigación es, casi de modo necesario, la hermenéutica, esa interpretación de los textos en su propio contexto. La principal labor para la realización de esta investigación ha sido fundamentalmente la búsqueda bibliográfica, que ha empezado través de las bibliotecas más cercanas, como la de la propia Universitat Jaume I, y por supuesto gracias a las nuevas tecnologías e internet. Así, algunas de las referencias importantes con las que contamos son la obra de de Kevin Lynch The image of the City; El espacio doméstico: la mujer y la Casa, de Atxu Amann, y Arquitectura y Género, de Mónica Cevedio o la obra de Carlos Hernández Pezzi, El Género de la Arquitectura: La Ciudad Compartida. Todas ellas, explican el papel que juegan las mujeres, como individuos de un género siempre vinculado a la Casa y a la esfera privada, y sobre las formas que adoptan las ciudades condicionando las formas de vida y de habitar.

\section{Resultados}

Tras los recientes episodios de auge urbanístico y de expansión inmobiliaria desmesurada, no sólo en nuestro ámbito territorial, sino tambien en otros muchos lugares del mundo occidental, cada vez son más las voces críticas con la forma de urbanizar y edificar que se ha llevado a cabo. Hemos vivido, y parece que seguiremos viviendo, en un tiempo en el que se ha sobrevalorado la individualidad y lo subjetivo. Las viviendas en su conjunto -muy a pesar de las unifamiliares o quizá por eso mismo- han tendido a alejarse de cualquier espacio de convivencia vecinal, cívica y generadora de vínculos entre las personas y que, además, son inherentes en nuestro ser, como animales sociales que somos en términos aristotélicos. La Casa ha evolucionado "desafortunadamente hacia una independencia total respecto a sus vecinos. [...] Cuando las parcelas se venden individualmente, los compradores suelen ser personas demasiado distintas por su formación y su estilo de vida para dar lugar a acciones comunes» (Moore, 1999: 257). De manera que esta evolución de la Casa ha ido configurando el sentido de la nueva ciudad: 
There seems to be a public image of any given city which is the overlap of many individual images. Or perhaps there is a series of public images, each held by some significant number of citizens. Such group images are necessary if an individual is to operate successfully within his environment and to cooperate with his fellows. Each individual picture is unique, with some content that is rarely or never communicated, yet it approximates the public image, which, in different environments, its more or less compelling, more or less embracing (Lynch, 1993: 46).

Sin embargo, la ciudad no es solo una imagen que observamos o incluso en la que vivimos, la ciudad tiene también un sentido puramente económico y mercantil, «not only is the city an object which is perceived (and perhaps enjoyed) by millions of people of widely diverse class and character, but it is the product of many builders who are constantly modifying the structure for reasons of their own» (Lynch, 1993: 2). Y esta ciudad, que es capaz de condicionar la vida de los ciudadanos, y que a su vez, esta pensada para albergar en ella la conocida sociedad de masas, hace que sus formas condicionen las relaciones de las personas, de manera que, como apunta Hannah Arendt "Lo que hace tan difícil soportar a la sociedad de masas no es el número de personas, sino el hechode que entre ellas el mundo ha perdido su poder para agruparlas, relacionarlas $y$ separarlas» (2005: 73).

$Y$ estas constantes modificaciones y cambios en las formas constructivas y de desarrollo urbano, nos muestran también como se ha privatizado -todavía más- la esfera privada, y se ha intentado consolidar un espacio aún más alejado a la realidad y esfera pública existente. Antes, la esfera privada simplemente se alejaba de la pública a través de sus muros y puertas; hoy, además de éstas, también se aleja mediante distancias kilométricas de los núcleos urbanos y de lo público. A pesar de ello, y en buena medida gracias a que vivimos en una sociedad que en su conjunto es mucho más consciente de la necesidad de luchar para la obtención de una igualdad real entre mujeres y hombres, este factor -la lejanía de los núcleos familiares- no ha sido causante de una mayor desigualdad en lo doméstico. Pero este gesto de conciencia social, no puede llevarnos a creer en la neutralidad de la arquitectura:

No debemos pensar que el arte o la arquitectura son «neutrales» en cuanto a género, ya que siempre han sido pensados, en masculino y han menospreciado y desvalorizado el arte o el espacio femenino. El arte o la arquitectura feminista son una reflexión en lo personal y en lo social, que no se quiere definir en relación a lo masculino. (Cevedio, 2003: 41).

Aunque tal vez haya sido este factor - el del alejamiento de los espacios-, en cierta manera, un elemento capaz de generar igualdad en cuanto a nuevas necesidades: necesidad de un transporte público o privado para llegar a otros lugares, e incluso reparto de tareas domésticas en relación con nuevas formas de gestionar el tiempo -un tiempo que se vería reducido por las longitudes a recorrer para realizar las actividades económicas para el sustento del hogar por los diferentes miembros de este núcleo-, y también jugaría un papel igualador en cuanto a considerar a la 
totalidad de personas como individuos en cuanto a consumidores en una sociedad mercantilizada y capitalista de consumo. Esto se debe en buena medida a que «la industria ha querido resolver un problema que no existía y muchos norteamericanos [y occidentales] han buscado lugares en los que el mundo que cada uno podía cuidar confortablemente estaba circunscrito por las fronteras de una parcela y la red de las autopistas que dan acceso" (Moore, 1999: 257).

Todo lo anterior, sumado a las técnicas de marketing que invaden la vida cotidiana de la contemporaneidad, ha logrado crear un falso imaginario que renuncia a uno de los primeros principios de las mujeres y los hombres, como células esenciales que conforman una sociedad, que es la convivencia en comunidad, la renuncia al sentimiento de pertenecer a un grupo social enmarcado dentro de una sociedad diferente e intercultural, de manera que "la publicidad y el mercado reducen todos los valores a precios. Vivimos en un nihilismo complaciente» (Baudelaire, cit. en Amann, 2011: 16). Y esto sucede en un momento en que las imágenes visuales lo abarcan todo, pues como apunta Cirici (2009: 35):

A la carretera i al carrer modern, a la nit, no veiem res que no sigui publicitat o senyalització. Si entrem a la vida individual, hi trobem la televisió [i també internet] [...] [però] de dia estarem dominats encara pel fabulós espectacle de l'urbanisme i l'arquitectura, amb el disseny dels vehicles.

En cierto modo podríamos considerar que es una nueva forma de ver la arquitectura, menos como una técnica o destreza en la que tiene un papel importante el diseño -aunque bien es cierto que éste también juega un papel indispensable para la conquista del público gracias a su conjugación de funcionalidad y estética- y más como otro paso en la cadena comercial para la venta de un producto, de manera que esta "parálisis intelectual de la arquitectura no es tanto una consecuencia de la mirada cínica y distante sobre los problemas metropolitanos, sino de la pretendida neutralidad de la ciudad construida por la postmodernidad sobre las ruinas del estilo internacional» (Hernández, 1998: 41).

Los espacios alejados de núcleos urbanos carecen, además, de las dotaciones físicas -y conceptuales- necesarias, deviniendo en que las mujeres ya no se constituyan -al menos en términos generales- como como un grupo de intereses comunes. Tampoco de intereses a nivel ciudadano, y es que los nuevos modelos urbanísticos, que comprenden diferentes formas de habitar, hacen que las agrupaciones sean más por otros perfiles que por los de género. De este modo, en un mundo en el que la esfera privada es totalmente privada y ajena por completo a la realidad pública y social exterior -aunque afortunadamente sí que exista una comunicación con una relación externa/interna gracias a las nuevas tecnologías, la generalización de Internet y los MassMedia- los casos de desigualdad que pudieran darse en ellos, podrían ser los peores de la historia. No sólo supondría un malestar absoluto para la mujer -que en tal caso ya sería víctima- sino que el hogar, el único espacio en el que tendría lugar su existencia, se convertiría en una prisión alejada e incomunicada 
del exterior. Un exterior -social- que generalmente suele ser necesario para ayudar a la víctima, y que, en estas circunstancias, desconocería esa situación y haciéndolo incapaz de poder hacer algo por solucionar esa situación. En definitiva, que estos espacios de reclusión pueden llegar a convertirse en verdaderas prisiones para las mujeres. $Y$ es que, como ya introdujo Carole Pateman en su Contrato Sexual (1995:220) "el esposo puede hacer que el hogar marital sea una prisión y aislar "a su esposaesclava de todo cariño salvo el de sí mismo, los hijos, los gatos u otros animñales domésticos"».

En el mundo actual, sobre todo en las sociedades occidentales, adentradas en una dinámica consumista que rige en casi la totalidad de nuestras relaciones sociales, las acciones cotidianas y también de nuestras formas de pensar y expresarnos, la arquitectura se ha convertido en un espectáculo cultural, y también en objeto de arte para disfrute de minorías, una arquitectura para la élite que cada vez pierde más conexión con la sociedad en su conjunto, y más aún si nos referimos a sociedades interculturales. Es un fenómeno cuyos fundamentos se encuentran muy vinculados al modelo urbanístico del denominado tract housing (Anexo: Fig. 9) que surgió en Estados Unidos tras la Segunda Guerra Mundial, y como apunta también Hernández Pezzi, es muy apreciable en las periferias de las urbes, lugares que son «objeto de culto de los arquitectos, son diferentes y homogéneas a la vez»; además, estos espacios «tienden a ser percibidos como partes fragmentarias de un único proceso evolutivo hacia la uniformidad" y acaban por convertirse en "representación del pensamiento único, que uniformiza la reflexión teórica para dar opción al disfraz de formas polivalentes en las que el mensaje es mercado, el contenido profundo es la especulación inmobiliaria sobre el suelo y el soporte banal es el edificio" (Hernández Pezzi, 1998: 36-38). En ese sentido, apuntaba Hanna Arendt (2005: 78) que «la sociedad de masas no sólo destruye la esfera pública sino también la privada, quita al hombre no sólo su lugar en el mundo sino también su hogar privado".

Con todo esto, algo tan importante como es el urbanismo, como elemento vertebrador de una ciudad, y también las propias viviendas, los hogares en sí mismos, acaban pasando de ser un espacio necesario e irrenunciable para las personas a ser un producto -como ya hemos apuntado- de un mercado cuyo valor oscila dependiendo de factores puramente económicos, entrando en una dinámica en la que los sentimientos y las experiencias se mercantilizan y las necesidades se convierten en nichos de mercado para la especulación. Todo ello tiene su proceso más arraigado en un espacio determinado, en las periferias urbanas, donde el remate final es la «homogeneización de formas de vida basadas en el modelo de motorización de la vida pública y mediatización televisiva de la vida privada» (Hernández Pezzi, 1998: 37), siendo además, que estos modelos y procesos homogeneizadores también afectan de forma importante al género.

Con todo esto, el núcleo urbano se ha convertido en un gran centro de producción, donde los servicios y el consumo son ilimitados. Un mundo en 
el que la rápida industrialización elimina constantemente las cosas de ayer para producir los objetos de hoy. Un espacio en el que el desarrollo urbano ha seguido caminos distintos a las tradiciones históricas de la planificación urbanística. Ni siquiera la tradicional denominada "mancha de aceite» es ya un adjetivo adecuado para las nuevas formas de la ciudad, que se ha convertido en continuo urbano reproductor de propuestas lineales, genéricas, indefinidas y universales tomadas de la contemporaneidad. La arquitectura, como señala Hernández Pezzi (1998: 39), "ha sufrido una involución hacia lo individual. La superficialidad de las propuestas, lo puntual de las soluciones y lo epigónico de su estética descomprometida, contribuyen a hacer de la arquitectura un objeto inservible para gran parte de la población». Pero esta involución se encuentra también dentro de un contexto global, donde lo exteriorizado (y por tanto, también la arquitectura) tiene un sentido meramente superflúo, dado que «nuestra sensación de la realidad depende por entero de la apariencia y, por lo tanto, de la existencia de una esfera pública. [...] Allí únicamente se tolera lo que es considerado apropiado, digno de verse u oírse. De manera que lo inapropiado se convierte automáticamente en asunto privado» (Arendt, 2005: 72).

En esta forma que adopta la urbe, entendida en todo momento como el conjunto de Casas en cuanto a hábitats vinculados con las personas que allí viven, también hay que tener en cuenta otra importante barrera: los círculos culturales que aparecen en las ciudades y en sus comunidades. Como señala Hernández Pezzi (1998: 40), «no es imposible en el multiculturalismo, aunque hay muchas formas de melting pot, que lejos de de producir un intercambio, alimentan discriminaciones repartidas uniformemente en barrios de muchos países». Y eso hace que no sea posible hablar de uniformidad en casi ningún aspecto -ni tan siquiera en aquellos negativos como las amenazas a la seguridad de la ciudadanía:

No es lo mismo hablar de uniformidad en Los Ángeles, afectada por un medio metropolitano, en el que prolifera la violencia urbana de los clanes y tribus urbanas, que en Estambul, donde la amenaza proviene del fundamentalismo de algunos grupos. [...] Mientras una ciudad es peligrosa en sus condiciones de habitabilidad por el vandalismo, la otra sigue siendo un lugar de encuentro en el que el riesgo principal proviene del terrorismo, la represión o el fundamentalismo, todos ellos dirigidos particularmente a acosar a las mujeres. (Hernández Pezzi, 1998: 40).

A pesar de todo esto, no podemos olvidar que para muchos individuos, no existe una discriminación real, ni tampoco un uso diferencial de los espacios de la ciudad y los hogares. En realidad es porque no existe una tradición lejana conocida $-y$ todavía menos reconocida- que haya recapacitado sobre ello, y tampoco sobre quién es el que determina el diseño urbanístico y espacial de una ciudad, su organización y la distribución de sus diferentes espacios, en la actualidad y a lo largo de la historia. El mismo Hernández nos recuerda, a partir de las ideas de la autora Brenda Vale, que esto es algo difícil de demostrar, y más todavía si existe una concepción de la vivienda, y de los elementos arquitectónicos 
que la conforman a ella y también a la ciudad, des-humanizada, y los entendemos como un producto propio de un mercado, más que como un elemento que nos ayuda -o debiera hacerlo- a mejorar nuestra calidad de vida y nuestro estado de ánimo. Entender los espacios y los elementos constructivos y arquitectónicos como un producto, significa deshumanizarlos. Y no sólo se hace desde las diferentes estructuras que determinan las formas de las ciudades en las que vivimos, o en cómo se diseñan los planos de nuestras Casas; también lo hacemos -los deshumanizamos- nosotros mismos, en la medida en que las propuestas estéticas que nos atraen -o suelen hacerlo- renuncian a fenómenos habituales comunes, e incluso naturales del ser y del habitar -en muchas ocasiones en las Casas, no queda rastro alguno de humanidad, porque hasta los elementos que nos recuerdan a ella, están colocados en una posición determinada y tienen un contenido concreto que reflejan un ideal o un modelo. Con ello estamos renunciando también a la escena doméstica o privada en la que realizamos nuestras vidas pero también en las que el papel tradicional de las mujeres durante toda la historia ha quedado también enmascarado, disimulado para que no pudiera verse, y mucho menos analizarse de forma crítica. Como señala Xavier Monteys, se intenta evitar cualquier vestigio de presencia humana en los espacios que se establecen como iconos o como modelos a seguir en la arquitectura actual de las viviendas:

Esto resulta especialmente significativo por cuanto, en demasiadas ocasiones, las imágenes de interiores domésticos que se muestran en las publicaciones de arquitectura parecen rehuir, de manera sistemática, la presencia de la gente y sus enseres; como si estos interiores ya estuvieran completos, sin necesidad o, si cabe, sin posibilidad, de ser amueblados y de ser habitados (Monteys, 2002: 14).

No es una tarea fácil acabar con problemáticas arraigadas desde la propia concepción de la idea, pero sí que es cierto que debemos tener una mirada crítica con las formas y los procedimientos a través de los que las ideas se transforman en realidades, porque en muchas ocasiones, estas realidades vienen dadas por una visión -tampoco tiene un porqué de ser malintencionada- sexista, que discrimina en cuanto a generar desigualdades en los propios espacios constructivos. Si bien no se trata de crear espacios neutros, sí se trata de hacer una apuesta por una forma más igualitaria entre las personas que viven y conviven en el hogar. Uno de los elementos fundamentales que generan esta problemática es que la tenencia, el uso y el reparto del suelo -y por tanto de la vivienda y el espacio- no está en manos de las mujeres en la misma medida que sí lo está en manos de los hombres, con independencia de referirnos a países industrializados o en vías de desarrollo. Esto todavía se agrava más si lo trasladamos a territorios específicos, y es que en el medio rural, las mujeres tienen todavía menos oportunidades que las mujeres que viven en la ciudad, dentro del país que sea en cualquier lugar del planeta.

Lo cierto es que las ciudades contemporáneas no han sabido dar una solución -al menos en su mayoría- a las necesidades de todos los 
miembros que conforman esta comunidad, y siempre ha seguido la concepción tradicional sin dar importancia a las realidades que reflejan los usos diferenciales en los espacios urbanos -y también domésticos-, de manera que el modelo de ciudad actual, generalmente, no ha sido capaz de solucionar los problemas que se arrastraban de otros momentos:

La ciudad sin forma, la ciudad emergente tras la reconstrucción después de la segunda guerra mundial que fue consolidada en plena época del desarrollismo, es el ejemplo más cercano a la observación de los déficits del planeamiento a la hora de establecer un marco participativo en las decisiones sobre las ciudades. Frente a las intenciones declaradas, el resultado social y físico es el más segregador de la época moderna, lo que confirma a muchos analistas que el estudio de los problemas del género en la ciudad no consiste sólo en comprobar los efectos de un uso diferencial -segregador y discriminatorio- del espacio, sino el de indagar acerca de una concepción diferente, verificar su existencia y sus causas para actuar de otra forma sobre ella (Hernández Pezzi, 1998: 54-55).

Se necesita, por tanto, una adaptación por parte de los arquitectos e ingenieros a las nuevas realidades urbanas y domésticas, sobre todo porque es necesaria una equiparación entre las personas, con independencia de su sexo, restaurando un orden urbano distinto al de hoy, en el que el género masculino siempre ha tenido una posición superior. Construir un nuevo modelo de ciudad para cambiarla a mejor es una tarea ilusionante, teniendo siempre claro que una planificación de los espacios nunca podrá ser neutra, y que esta neutralidad tampoco será capaz de servir al conjunto de los ciudadanos para compartir la ciudad (Hernández Pezzi, 1998: 35). Eso mismo ocurre con los objetos que conforman el interior de las viviendas, y por eso observamos cómo determinados productos relacionados con el diseño llegan a configurarse de manera distinta dependiendo de quién sea -y que género tenga- su autor, y ello se ve muy bien en el espacio doméstico, ya que «las mujeres, por su historia, por las funciones que les han sido atribuidas, tienen un bagaje aprovechable para el diseño de objetos destinados a la Casa. No se trataba tanto de diseño de mujeres como de diseño de personas que, por su experiencia en determinados ambientes, pudieran ofrecer planteamientos distintos» (Torrent y Marín, 2002: 31). Pero ello no significa tampoco que haya que negar todos los modelos de objetos y enseres existentes hasta el momento, pero sí que hay que ser consciente de que «los modelos existentes son casi siempre masculinos y no se trata de desechar estos modelos y escoger otros, porque no los hay, sino de que las mujeres hablen. Y lo hagan desde una posición que es totalmente distinta a la de los hombres» (Torrent y Marín, 2002: 32).

Es importante también, como respuesta a las necesidades actuales, ganar en conciencia cívica. Hay que ser capaces de crear una comunidad centrada en las cualidades inherentes del lugar sin alejarse significativamente de su esplendor natural. Las Casas se configuran como espacios interiores, pero también exteriores, y por ello tienen que entenderse como una continuidad del paisaje en el que se encuentran 
ubicadas, formando parte de él de la forma más natural posible: integrándose en el propio paisaje. Pero para hacer Casas mejores, necesitamos construir -o preservar- mejor también los paisajes, y para ello, tal vez tengamos que renunciar a determinadas jerarquías formales que admiramos - de hecho, algunos grandes edificios domésticos están basados en precedentes feudales. Cevedio (2003: 42) recuerda que a partir de 1979 en el Congreso de Mujeres de las Ciencias Naturales y la Tecnología en Hamburgo «se han buscado nuevas formas y programas arquitectónicos, con los que la mujer arquitecta se identifique, como viviendas ecológicas y viviendas integradas en el paisaje; viviendas, en definitiva más humanas».

A pesar de estas respuestas, no tenemos que olvidar otros atributos ligados en gran medida a lo estético en cuanto que son generadores de experiencias visuales y estéticas-que muchas veces pasan desapercibidos, y que "por regla general todo el mundo tilda de "no necesarias", "que son como de lujo", "para distraerse", "poco prácticas"..., y que sin embargo tanto deseamos, buscamos y tanto, por lo demás, pienso que estamos necesitadas de ellas» (Rambla, 2007: 24). Nos referimos a que "para que los lugares en que vivimos reflejen el acto de vivir deben hundir sus raíces en el presente, en la suavidad de los lugares y las familias. [...] Todo espacio debería pertenecer a algo tangible, como un bosquecillo o un arroyo, a una calle activa o una forma evocadora» (Moore, 1999: 259) y con ello será más fácil que la Casa y el entorno de esta nos resulte más atractivo, más saludable y sobretodo mejor para desarrollar nuestras vidas con independencia de nuestro género, y la forma de hacerlo será detectando "cómo funciona el sistema, desarticulando y deconstruyendo los espacios que habitamos" (Cevedio, 2003: 44)

A este espacio físico -interior, exterior y su marco- también hay que dotarlo de «tres elementos parar lograr unos lugares de residencia satisfactorios: buenos vecinos, las instituciones que estos buenos vecinos seguramente suministrarán y "buenas salidas" " (Frederick Law Omsted, cit. en Moore, 1999: 261). Una buena convivencia es fundamental para poder vivir con calidad de vida, y para ello es elemental tener buenos vecinos -quienes son los buenos vecinos, lo determina el propio carácter e inquietudes de cada individuo- y de estas inquietudes comunes se forjará un ideario colectivo relativo no sólo a cuestiones importantes para la mejora de la comunidad que dará lugar a unas instituciones -al menos de carácter local- adaptadas a las necesidades y demandas de quienes allí viven. También es muy significativo el espacio de ocio, y la calidad de éste, en cuanto a oferta cultural y deportiva. Con estas condiciones que son un elemento clave para el desarrollo de la vida social, se puede configurar un espacio mejor y más igualitario propio de una sociedad a la altura de las demandas éticas y sociales de la actualidad. En cuanto a mejora del espacio físico, también en la actualidad vemos cómo el espacio físico público, en muchas ocasiones, ha mejorado considerablemente, tanto que es capaz de ofrecernos iguales o superiores experiencias positivas que nuestra propia Casa. La «sociedad interdependiente en la que vivimos puede reflejarse en 
lugares plenamente habitados donde los espacios que se usan comunitariamente sean tan variados y estén tan ricamente impregnados de cuidados personales como los lugares privados en los que moramos" (Moore, 1999: 261).

La realidad es que entorno y Casa forman parte de un mismo total, de un conjunto en el que es necesario que se den una serie de características para que las personas puedan desarrollarse en plenitud, y que se dé una vida mejor. Para ello este elemento inherente al hogar, de la misma forma que la propia Casa, tiene que ser también capaz de propiciar esa conexión, y en ese sentido:

\begin{abstract}
Necesitamos un entorno que podamos comprender a la manera que comprendemos las Casas: como lugares hechos por y para las personas, donde los procesos de ordenación e intercambio sistemáticos que subyacen en nuestra civilización queden a nuestro alcance. [...] Necesitamos lugares donde las personas puedan ejercitar su voluntad y gozar de la buena disposición de los demás dentro de una configuración de acuerdos físicamente enraizada en el lugar; más duradero que -pero animado por- los intereses transitorios de aquellos que pueden darle siempre nueva vida y nuevo interés (Moore, 1999: 262).
\end{abstract}

Con todo esto, defendemos lo que acertadamente Hannah Arendt (2005: 75) apunto diciendo que «si el mundo ha de incluir un espacio público, no se puede establecer para una generaciones y planearlo sólo para los vivos, sino que debe superar el tiempo vital de los hombres mortales». Y para poder lograr esto, necesitamos «una revolución de la vida cotidiana y de las costumbres, forjar una nueva concepción del mundo $y$, muy especialmente, una nueva relación entre los sexos» (Ana de Miguel, cit. en Cevedio, 2003: 95). 


\section{Bibliografía}

\section{Vir. Bibliografia}

Amann AlCoCer, Atxu (2011): Mujer y Casa, Madrid, Universidad Complutense de Madrid.

ARENDT, Hannah (2005): La condición humana, Madrid, Paidós.

CEVEDIO, Mónica (2009): Arquitectura y Género. Espacio Público/Espacio Privado, Madrid, Icaria.

CIRICI, Alexandre (2009): Art i Societat, Barcelona, Obrador Edèndum.

Hernández PezZI, Carlos (1998): El género de la Arquitectura La ciudad Compartida, Madrid, Consejo superior de colegios de Arquitectos de España

LYNCH, Kevin (1993): The image of the city, USA, The Mit Press

MONTEYS, Xavier y otros (2002): Casa collage. Un ensayo sobre la arquitectura de la Casa, Barcelona, G. Gili.

MOORE, Charles y otros (1999): La Casa: forma y diseño, Barcelona, G. Gili.

PATEMAN, Carole (1995): El contrato sexual, Barcelona, Anthropos.

RAMBLA, Wenceslao (2007): Estética y Diseño. Salamanca, Universidad Salamanca.

TORRENT, Rosalía y MARín, Juan Manuel (2002): Sandra Figuerola+Marisa Gallén.

Disseny i Comunicació, sèrie dissenyadors valencians, número 7, Castelló, Universitat Jaume I y Ajuntament de Castelló.

\section{MATERIAL GRÁFICO}

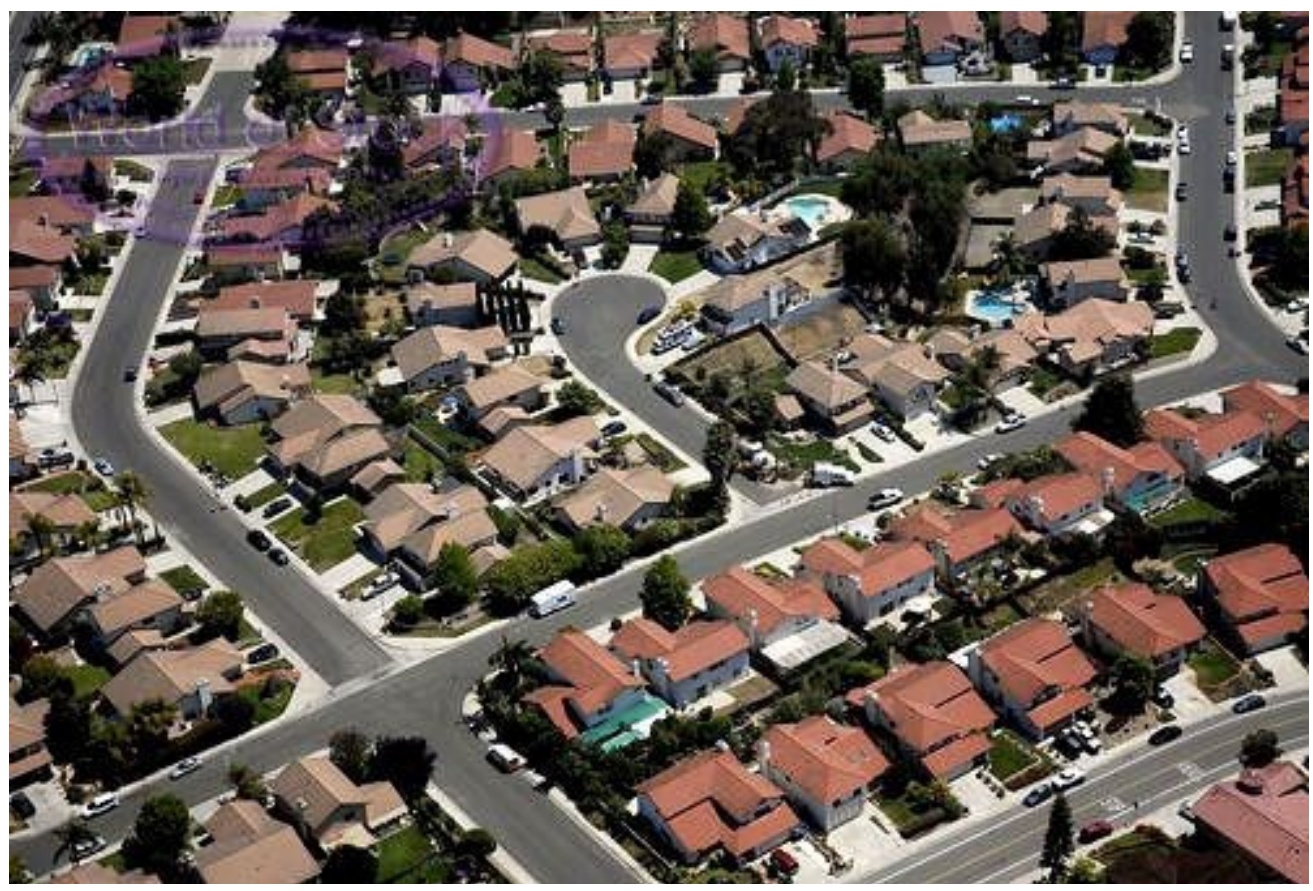

Figura 1. Ejemplo de desarollo urbano uniforme, o tract housing. San Francisco, Estados Unidos. 